\title{
The prevalence and risk factors of group B streptococcus colonization in Iranian pregnant women
}

\author{
Roksana Darabi ${ }^{1}$, Sima Tadi ${ }^{1}$, Mitra Mohit ${ }^{1}$, Erfan Sadeghii, ${ }^{2,3}$, Gita Hatamizadeh ${ }^{1}$, Bahareh Kardeh $^{4}$, Mina \\ Etminan-Bakhsh ${ }^{1}$, Yekta Parsa ${ }^{5}$
}

${ }^{1}$ Department of Obstetrics and Gynecology, Tehran Medical Sciences Branch, Islamic Azad University, Tehran, Iran

${ }^{2}$ Students Research Committee, Kermanshah University of Medical Sciences, Kermanshah, Iran

${ }^{3}$ Department of Biostatistics and Epidemiology, School of Public Health, Isfahan University of Medical Sciences, Isfahan, Iran

${ }^{4}$ Student Research Committee, Shiraz University of Medical Sciences, Shiraz, Iran

${ }^{5}$ Young Researchers and Elite Club, Tehran Medical Sciences Branch, Islamic Azad University, Tehran, Iran

\section{Type of article: Original}

\begin{abstract}
Background: Group B Streptococcus (GBS) is a leading cause of serious neonatal infections. Although great progress has been made in preventing prenatal GBS, its colonization rate in different regions of Iran remains unknown.

Aim: To determine GBS colonization prevalence and its risk factors among Iranian pregnant women.

Methods: This prospective cross-sectional study was performed on 186 pregnant women, who attended Boo-Ali hospital which is affiliated with Islamic Azad University in Tehran, Iran, from March 2014 to June 2015. The demographic, obstetric and gynecological data were gathered. A recto-vaginal culture was taken from each patient, with a sterile swab, in lithotomy position without using speculum, and vaginal $\mathrm{pH}$ was measured. Patients with positive GBS received IV antibiotic therapy during labor (penicillin G 3 gram at first dose then 1.5 gram $\mathrm{Q} / 4 \mathrm{~h}$ until delivery). Data were analyzed by statistical software SPSS version 21. Statistical tests for differences were performed by Chi-square test. Potential confounding was assessed by logistic regression. Level of significance was set at $\mathrm{p}<0.05$.

Results: Twenty-two (11.8\%) patients had positive recto-vaginal colonization. No significant differences between colonized and GBS-negative women with regard to age, obstetrics history and socio-economic factor were noticed. In contrast, smoking, history of previous infection with HPV, presence of vulvitis and a vaginal $\mathrm{pH}>4.5$ were associated with GBS colonization $(\mathrm{p} \leq 0.05)$.

Conclusions: With a relatively low prevalence and few significantly correlated factors, it is hardly possible to define a high risk group of pregnant women for GBS colonization. Therefore, thorough measures should be taken in order to prevent infection complications in mothers and neonates in the Iranian population.

Keywords: Group B Streptococcus, Prevalence, Risk Factors, Pregnant Women, Vertical Infection Transmission, Colonization
\end{abstract}

\section{Corresponding author:}

Mina Etminan-Bakhsh, Medical Research Center, Azad University of Medical Sciences, Attarimoqaddam Ave, Haqani Ave, Dr. Shariati St, Tehran, Iran, P. O. BOX: 19395-1495, Tehran, Iran.

Tel: +9821-22006660, Fax:+9821-22846593, Email: mina_etminan@yahoo.com

Received: May 18, 2016, Accepted: September 17, 2016, Published: May 2017

iThenticate screening: September 10, 2016, English editing: November 22, 2016, Quality control: April 01, 2017

(C) 2017 The Authors. This is an open access article under the terms of the Creative Commons Attribution-NonCommercialNoDerivs License, which permits use and distribution in any medium, provided the original work is properly cited, the use is non-commercial and no modifications or adaptations are made. 


\section{Introduction}

\subsection{Background and study logic}

Colonization of group B Streptococcus (GBS), a gram positive coccus, in the vagina and perianal regions, is considered as a risk factor for subsequent infections in pregnant women (1). Maternal streptococcal colonization is associated with urinary tract infection, premature rupture of membrane (PROM), preterm labor, intrauterine fetal death and complications such as chorioamnionitis and endometritis (2). Pregnant women who are carriers of GBS have $50-60 \%$ potential capacity for vertical transmission of the microorganism, through which $1-2 \%$ of their newborns develop invasive GBS infection $(1,3)$, with $5-20 \%$ mortality rate and serious complications, especially among premature neonates $(4,5)$. Ethnicity, African origin, maternal age, parity, marital status, socio-economic status, education, occupation, geographic location, smoking, presence of sexually transmitted disease, sexual behavior, and high body mass index have been reported to influence the prevalence of colonization $(2,3,6)$. The Centers for Disease Control and Prevention (CDC) currently recommend screening of all pregnant women for GBS between 35-37 weeks of gestation $(2,5,7)$. Based on recommended guidelines, intra-partum administration of antibiotics in high risk groups like premature deliveries (before 37 weeks), PROM longer than 18 hours, fever higher than $38^{\circ} \mathrm{c}(8)$, previous history of infant with GBS infection and also in women with positive screening test of GBS, lowers the risk of neonatal GBS infection (1, 8-10). The prevalence of GBS vaginal colonization in pregnant women in alternative studies was as follows: India/Pakistan 12\%, America 14\%, Asia-Pacific 19\%, Sub-Saharan Africa $19 \%$, and Middle-East/North Africa 22\% (11). Although there is insufficient evidence regarding the prevalence of GBS colonization among Iranian pregnant women, in Jahromi et al. study in Zeynabieh Hospital, Shiraz, Iran, 9.1\% of 1,197 pregnant patients had positive GBS recto-vaginal culture with $60 \%$ transmission rate to their neonates (3).

\subsection{Objectives}

Considering the paucity of data about GBS colonization among Iranian pregnant women, this study was conducted to determine the prevalence of GBS colonization and its risk factors in pregnant women who attended Boo-Ali hospital, a teaching center of Islamic Azad University in Tehran, Capital of Iran.

\section{Material and Methods}

\subsection{Research design}

This prospective cross-sectional study was performed on pregnant women, who attended Boo-Ali hospital which is affiliated with Islamic Azad University in Tehran, Iran, from March 2014 to June 2015.

\subsection{Selection criteria}

Pregnant women, who volunteered, with gestational age between 35-37 weeks, were eligible to enroll in the study. Patients with any symptoms or signs of urinary tract infection during the past 4 weeks, intake of antibiotics during the past 2 weeks, and preexisting medical disorders complicating pregnancy, were excluded from the study.

\subsection{Data collection}

At the baseline, a gynecologist examined all patients. In addition, demographic, obstetric and gynecological data, as well as information on previous gestations (including history of PROM and early neonatal sepsis) were gathered.

\subsection{Sample Size Estimation}

Cochran's formula was used to estimate sample size. According to Jahromi et al. (3), the approximate prevalence of GBS colonization in Iran is 9.1\%. Using Cochran's sample size formula, with a margin error of 5\% and confidence interval of $95 \%$, a sample of 126 patients were required. The formula was as follows: $n=z^{2} p q / e^{2}$. Similar sample size was determined using Morgan's table. We interviewed 200 pregnant women, of whom 14 subjects were excluded according to the previously mentioned exclusion criteria. Finally, a total of 186 women participated in this study; higher than estimated sample size.

\subsection{GBS Culture}

A recto-vaginal culture was taken from each patient, with a sterile swab in lithotomy position without using speculum, and vaginal $\mathrm{pH}$ was measured. The swabs were inoculated into Amies transport medium and transported to the microbiology research laboratory. The swabs were then removed from the Amies medium and inoculated in Todd-Hewitt broth, supplemented with gentamicin $(8 \mathrm{mg} / \mathrm{ml})$ and nalidixic acid $(15 \mathrm{mg} / \mathrm{ml})$. The inoculated samples were incubated for 24 hours at $37{ }^{\circ} \mathrm{C}$. The broth was then subcultured onto a Columbia Agar base with $5 \%$ sheep blood, under the same conditions. Colonies suggestive of S. agalactiae (due to presentation of a narrow zone of betahemolysis) were subjected to catalase and CAMP tests. Negative blood-agar plates were re-incubated for an 
additional 18 to 24 hours. Patients with positive GBS received IV antibiotic therapy during labor (penicillin G 3 gram at first dose then 1.5 gram $\mathrm{Q} / 4 \mathrm{~h}$ until delivery).

\subsection{Statistical analysis}

Data were analyzed by statistical software SPSS version 21. Statistical tests for differences were performed by Chisquare test. Potential confounding was assessed by logistic regression. Level of significance was set at $\mathrm{p}<0.05$.

\subsection{Research ethics}

The study was approved by the ethical committee of Islamic Azad University, Tehran Medical Sciences Branch, and written informed consent for participation was obtained.

\section{Results}

In total, 186 volunteer pregnant women aged 18-35 years, who met the inclusion criteria, were evaluated. Twentytwo $(11.8 \%)$ patients had positive recto-vaginal colonization. The mean age of participants was $27.91 \pm 5.03$ years, ranging from 17 to 41 years. The mean ages of GBS-positive and negative women were $28.77 \pm 4.4$ and $27.79 \pm 5.11$ years, respectively $(\mathrm{p}=0.396)$. Socio-economic characteristics related to GBS colonization is shown in Table 1 . No significant difference between colonized and GBS-negative women with regard to socio-economic factor was noticed. Logistic regression analysis showed that smoking ( $\mathrm{p}=0.001$, CI: 1.23-83.2), history of previous infection with HPV ( $\mathrm{p}=0.006$, CI: $2.08-34.32)$ and presence of vulvitis ( $\mathrm{p}=0.041$, CI: $-0.72-27.92)$ were associated with GBS colonization. In addition, women with a vaginal $\mathrm{pH}>4.5$ were more likely to be colonized than those who had vaginal $\mathrm{pH} \leq 4.5(\mathrm{p}=0.488)$. Indeed, the rate of GBS colonization was $70 \%$ higher by each one unit increased $\mathrm{pH}$. However, there was no significant difference in colonization rate in terms of sexual intercourses/week during or pre pregnancy, history of neonate sepsis, history of preterm labor, PROM, PID, previous infection with HSV, vaginal discharge, vaginal candidiasis, rectal coitus, vaginal burning and miscarriages in previous pregnancies ( $\mathrm{p}>0.05)$. Odd ratios for all variables associated with GBS colonization are shown in Table 2.

Table 1. Gestational and socio-demographic characteristics in GBS-positive and -negative pregnant women

\begin{tabular}{|c|c|c|c|c|}
\hline \multirow{2}{*}{\multicolumn{2}{|c|}{ Variables }} & \multicolumn{2}{|c|}{ GBS colonization } & \multirow[t]{2}{*}{ p-value } \\
\hline & & Positive $(n=22)$ & Negative $(n=164)$ & \\
\hline \multicolumn{2}{|c|}{ Mean maternal age (years) $\pm \mathrm{SD}$} & $28.77 \pm 4.4$ & $27.79 \pm 5.11$ & 0.396 \\
\hline \multirow[t]{3}{*}{ Educational level } & Illiterate & $2(9)$ & $45(27.4)$ & \multirow[t]{3}{*}{0.163} \\
\hline & High school diploma & $10(45.4)$ & $65(39.6)$ & \\
\hline & Academic & $10(45.4)$ & $54(32.9)$ & \\
\hline \multirow[t]{2}{*}{ Employment status } & Employed & $5(22.7)$ & $27(16.4)$ & \multirow{4}{*}{$<0.001^{*}$} \\
\hline & Unemployed & $17(77.3)$ & $137(83.6)$ & \\
\hline \multirow[t]{2}{*}{ Smoking } & Yes & $2(9)$ & $1(0.6)$ & \\
\hline & No & $20(91)$ & $163(99.4)$ & \\
\hline \multirow[t]{4}{*}{ Parity } & Nulliparity & $11(50)$ & $85(51.8)$ & \multirow{4}{*}{0.421} \\
\hline & 1 & $11(50)$ & $63(38.4)$ & \\
\hline & 2 & $0(0)$ & $15(9.1)$ & \\
\hline & $\geq 3$ & $0(0)$ & $1(0.7)$ & \\
\hline \multicolumn{2}{|c|}{ Mean gestational age (week) \pm SD } & $36 \pm 0.87$ & $35.81 \pm 2.78$ & 0.760 \\
\hline
\end{tabular}

Values are given as number (percentage) in subgroup

* Significant 
http://www.ephysician.ir

Table 2. Association between Reproductive history and pregnancy related characteristics of the subjects according to GBS colonization status

\begin{tabular}{|c|c|c|c|c|c|c|}
\hline \multirow{2}{*}{\multicolumn{2}{|c|}{ Variables }} & \multirow{2}{*}{\multicolumn{2}{|c|}{ GBS colonization; $\mathrm{n}(\%)$}} & \multirow{2}{*}{\multicolumn{2}{|c|}{$\begin{array}{l}95 \% \text { CI for } \% \text { of positive } \\
\text { GBS }\end{array}$}} & \multirow{3}{*}{$\begin{array}{l}\begin{array}{l}\mathrm{p}- \\
\text { value }\end{array} \\
0.096\end{array}$} \\
\hline & & & & & & \\
\hline \multirow{3}{*}{$\begin{array}{l}\text { Previous } \\
\text { miscarriages }\end{array}$} & 0 & $\begin{array}{l}\begin{array}{l}\text { Positive } \\
(\mathrm{n}=22)\end{array} \\
15(68.2)\end{array}$ & $\begin{array}{l}\begin{array}{l}\text { Negative } \\
(n=164)\end{array} \\
134(81.7)\end{array}$ & 4874 & 8766 & \\
\hline & 1 & $7(31.8)$ & $24(14.6)$ & 12.34 & 5126 & \\
\hline & $\geq 2$ & $0(0)$ & $6(3.7)$ & 0 & 0 & \\
\hline \multirow[t]{2}{*}{ PROM $^{\mathrm{a}}$} & Pos & $2(9.1)$ & $9(5.5)$ & -2.92 & 21.12 & \multirow[t]{2}{*}{0.506} \\
\hline & Neg & $20(90.9)$ & $155(94.5)$ & 78.88 & 102.92 & \\
\hline \multirow[t]{2}{*}{ Preterm labor $^{\mathrm{a}}$} & Pos & $1(4.5)$ & $6(3.7)$ & -4.16 & 13.16 & \multirow[t]{2}{*}{0.838} \\
\hline & Neg & $21(95.5)$ & $158(96.3)$ & 86.84 & 104.16 & \\
\hline \multirow[t]{2}{*}{ Rectal coitus } & Pos & $3(13.6)$ & $39(23.8)$ & -0.72 & 27.92 & \multirow[t]{2}{*}{0.293} \\
\hline & Neg & $19(86.4)$ & $125(76.2)$ & 72.08 & 100.72 & \\
\hline \multirow[t]{4}{*}{ N.I.P.P } & $\begin{array}{l}\text { More than 1-2 per } \\
\text { week }\end{array}$ & $4(18.2)$ & $42(25.6)$ & 2.08 & 34.32 & \multirow[t]{4}{*}{0.772} \\
\hline & $1-2$ per month & $1(4.5)$ & $13(7.9)$ & -4.16 & 13.16 & \\
\hline & $\begin{array}{l}\text { lower than } 1-2 \text { per } \\
\text { month }\end{array}$ & $1(4.5)$ & $5(3)$ & -4.16 & 13.16 & \\
\hline & 1-2 per week & $16(72.7)$ & $104(63.4)$ & 54.08 & 91.32 & \\
\hline \multirow[t]{4}{*}{ N.I.D.P } & $1-2$ per week & $9(40.9)$ & $53(32.3)$ & 20.36 & 61.44 & \multirow[t]{4}{*}{0.587} \\
\hline & $\begin{array}{l}\text { More than 1-2 per } \\
\text { week }\end{array}$ & $2(9.1)$ & $13(7.9)$ & -2.92 & 21.12 & \\
\hline & $1-2$ per month & $5(22.7)$ & $62(37.8)$ & 5.2 & 40.2 & \\
\hline & Never & $6(27.3)$ & $36(22)$ & 8.68 & 45.92 & \\
\hline \multirow[t]{2}{*}{$\mathrm{PID}^{\mathrm{a}}$} & Pos & $2(9.1)$ & $5(3)$ & -2.92 & 21.12 & \multirow[t]{2}{*}{0.183} \\
\hline & Neg & $20(90.9)$ & $159(97)$ & 78.88 & 102.92 & \\
\hline \multirow[t]{2}{*}{$\mathrm{HPV}^{\mathrm{a}}$} & Pos & $4(18.2)$ & $5(3)$ & 2.08 & 34.32 & \multirow[t]{2}{*}{$0.006^{*}$} \\
\hline & Neg & $18(81.8)$ & $159(97)$ & 65.68 & 97.92 & \\
\hline \multirow[t]{2}{*}{$\mathrm{HSV}^{\mathrm{a}}$} & Pos & $2(9.1)$ & $4(2.4)$ & -2.92 & 21.12 & \multirow[t]{2}{*}{0.123} \\
\hline & Neg & $20(90.9)$ & $160(97.6)$ & 78.88 & 102.92 & \\
\hline \multirow{2}{*}{$\begin{array}{l}\text { History of neonate } \\
\text { sepsis }\end{array}$} & Pos & $1(4.5)$ & $9(5.5)$ & -4.16 & 13.16 & \multirow[t]{2}{*}{0.854} \\
\hline & Neg & $21(95.5)$ & $155(94.5)$ & 86.84 & 104.16 & \\
\hline \multirow[t]{2}{*}{ Vaginal discharge } & Pos & $1(4.5)$ & $4(2.4)$ & -4.16 & 13.16 & 0.573 \\
\hline & Neg & $21(95.5)$ & $160(97.6)$ & 86.84 & 104.16 & \\
\hline Vaginal pruritus & Pos & $3(13.6)$ & $16(9.8)$ & -0.72 & 27.92 & 0.575 \\
\hline & $\mathrm{Neg}$ & $19(86.4)$ & $148(90.2)$ & 72.08 & 100.72 & \\
\hline Vaginal Burning & Pos & $2(9.1)$ & $14(8.5)$ & -2.92 & 21.12 & 0.931 \\
\hline & Neg & $20(90.9)$ & $150(91.5)$ & 78.88 & 102.92 & \\
\hline Vulvitis & Pos & $3(13.6)$ & $6(3.7)$ & -0.72 & 27.92 & $0.041^{*}$ \\
\hline & Neg & $19(86.4)$ & $158(96.3)$ & 72.08 & 100.72 & \\
\hline Vaginal candidiasis & Pos & $5(22.7)$ & $23(14)$ & 5.2 & 40.2 & 0.289 \\
\hline & Neg & $17(77.3)$ & $141(86)$ & 59.8 & 94.8 & \\
\hline Vaginal $\mathrm{pH}$ & $\leq 4.5$ & $16(72.7)$ & $107(65.2)$ & 54.08 & 91.32 & 0.488 \\
\hline & $>4.5$ & $6(27.3)$ & $57(34.8)$ & 8.68 & 45.92 & \\
\hline
\end{tabular}

N.I.P.P: Number of intercourse pre pregnancy; N.I.D.P: Number of intercourse during pregnancy; PROM: Premature rupture of membranes; PID: Pelvic inflammatory diseases; Pos: Positive; Neg: Negative; ${ }^{a}$ Previous gestation; * Significant

\section{Discussion}

Even today, vertical transmission of GBS affects neonates as the most frequent infection responsible for sepsis in developing and developed nations (12). Although screening and prophylactic treatments have helped decrease mortality rates to 5\%, a clear estimation of disease burden in many developing countries remains unrecognized (13). This cross-sectional study was conducted on Iranian pregnant women with the aim of investigating a wide range of 
possible risk factors associated with GBS colonization for the first time. The findings of the present study revealed an $11.8 \%$ GBS colonization rate among participants, almost similar to another population based study in Iran, which reported a $9.1 \%$ carrier rate (3). Worldwide reports of GBS carriage prevalence estimated a $10 \%$ to $30 \%$ rate (14). It seems that Iranian women have a relatively low prevalence of GBS colonization. However, the variety in statistics can also be a result of other confining factors such as site and technique of culturing, as well as gestational age. Even though previous history of GBS colonization is a great risk factor (15), it should be noted that the status of colonization might be transient, intermittent or even chronic (16), thus mothers should be evaluated in each pregnancy. Despite the fact that preterm labor and ROM were introduced as remarkable complications of GBS colonization (3), no significant statistical difference was detected in carrier and non-carrier populations of our study. Furthermore, no risk factors correlating the socio-economic status, obstetrics and gynecological history and sexual activity were recognized. In general, our findings indicated that no high risk group can be identified with regards to age, parity or socio-economic variables, which has also had controversial results in different studies. In this regard, our results are in consistence with a study in the Netherlands by Arijaan et al. on 1,702 women from 72 countries (17). Despite various associated factors introduced in previous literature, including bacterial vaginosis, recent vaginal intercourse, vaginal washing (18), colonization in prior pregnancy (19), and body mass index, typical intrapartum risk factors and positive screens are lacking in many infants, who are affected with GBS infection (20). With a relatively low prevalence and few significantly correlated factors, it is hardly possible to define a high risk group of pregnant women for GBS colonization. Therefore, thorough measures should be taken in order to prevent infection complications in mothers and neonates in the Iranian population.

\section{Conclusions}

The findings of the present study revealed an $11.8 \%$ GBS colonization rate among participants, and indicated that vulvitis, smoking, HPV infection and vaginal $\mathrm{pH}$ were correlated with risk of GBS colonization. Therefore, it is suggested that women with these associated factors may benefit from prophylactic antibiotic therapy, or when possible, a second culture shortly before delivery. In addition, it can be concluded that screening for HPV or cervical cancer is of greater importance in GBS positive patients. To optimize the prophylactic treatment, it is best to consider local prevalence rate and risk factors, which helps in clinical decision making, based on risk factor approach, when routine recto-vaginal culturing is not cost-effective in clinical settings. Hence, more studies with a larger sample size are suggested.

\section{Acknowledgments:}

We are grateful to Dr. Majeed Mokhtari (Boo-Ali hospital), who is affiliated with Islamic Azad University in Tehran, Iran, for his technical support. This study was supported by Islamic Azad University, Tehran Medical Sciences Branch, Tehran, Iran. The funding organizations had no role in the design and conduct of the study; collection, management, and analysis of the data; or preparation, review, and approval of the manuscript.

\section{Conflict of Interest:}

There is no conflict of interest to be declared.

Authors' contributions:

All authors contributed to this project and article equally. All authors read and approved the final manuscript.

\section{References:}

1) Sharmila V, Joseph NM, Arun Babu T, Chaturvedula L, Sistla S. Genital tract group B streptococcal colonization in pregnant women: a South Indian perspective. J Infect Dev Ctries. 2011; 5(8): 592-5. doi: 10.3855/jidc.1551. PMID: 21841303.

2) Rocchetti TT, Marconi C, Rall VL, Borges VT, Corrente JE, da Silva MG. Group B streptococci colonization in pregnant women: risk factors and evaluation of the vaginal flora. Arch Gynecol Obstet. 2011; 283(4): 717-21. doi: 10.1007/s00404-010-1439-8. PMID: 20349243.

3) Namavar Jahromi B, Poorarian S, Poorbarfehee S. The prevalence and adverse effects of group B streptococcal colonization during pregnancy. Arch Iran Med. 2008; 11(6): 654-7. doi: 10.1016/j.pedneo.2011.05.008. PMID: 18976037.

4) $\mathrm{Yu}$ HW, Lin HC, Yang PH, Hsu CH, Hsieh WS, Tsao LY, et al. Group B streptococcal infection in Taiwan: maternal colonization and neonatal infection. Pediatr Neonatol. 2011; 52(4): 190-5. doi: 10.1016/j.pedneo.2011.05.008. PMID: 21835363. 
5) Marconi C, Rocchetti TT, Rall VL, Carvalho LR, Borges VT, Silva MG. Detection of Streptococcus agalactiae colonization in pregnant women by using combined swab cultures: cross-sectional prevalence study. Sao Paulo Med J. 2010; 128(2): 60-2. PMID: 20676570.

6) Mavenyengwa RT, Afset JE, Schei B, Berg S, Caspersen T, Bergseng H, et al. Group B Streptococcus colonization during pregnancy and maternal - fetal transmission in Zimbabwe. Acta Obstet Gynecol Scand. 2010; 89(2): 250-5. doi: 10.3109/00016340903398029. PMID: 19916889.

7) Yang MJ, Sun PL, Wen KC, Chao KC, Chang WH, Chen CY, et al. Prevalence of maternal group B streptococcus colonization and vertical transmission in low-risk women in a single institute. J Chin Med Assoc. 2012; 75(1): 25-8. doi: 10.1016/j.jcma.2011.10.011. PMID: 22240533.

8) Berardi A, Lugli L, Baronciani D, Rossi C, Ciccia M, Creti R, et al. Group B Streptococcus early-onset disease in Emilia-Romagna: review after introduction of a screening-based approach. Pediatr Infect Dis J. 2010; 29(2): 115-21. doi: 10.1097/INF.0b013e3181b83cd9. PMID: 19915512.

9) Barcaite E, Bartusevicius A, Tameliene R, Maleckiene L, Vitkauskiene A, Nadisauskiene R. Group B streptococcus and Escherichia coli colonization in pregnant women and neonates in Lithuania. Int J Gynaecol Obstet. 2012; 117(1): 69-73. doi: 10.1016/j.ijgo.2011.11.016. PMID: 22265188.

10) Müller-Vranješ A, Puntarić D, Čuržik D, Šijanović S, Topolovec Z, Kasač Z, et al. Prevalence and Significance of Vaginal Group B Streptococcus olonization in Pregnant Women from Osijek, Croatia. Coll Antropol. 2011; 35(1): 21-6. PMID: 21661350.

11) Chaudhry BY, Akhtar N, Balouch AH. Vaginal carriage rate of group B Streptococcus in pregnant women and its transmission to neonates. J Ayub Med Coll Abbottabad. 2010; 22(4): 167-70. PMID: 22455289.

12) Baker CJ. The spectrum of perinatal group B streptococcal disease. Vaccine. 2013; 31(4): 3-6. doi: 10.1016/j.vaccine.2013.02.030. PMID: 23973344.

13) Johri AK, Lata H, Yadav P, Dua M, Yang Y, Xu X, et al. Epidemiology of Group B Streptococcus in developing countries. Vaccine. 2013; 31(4): 43-5. doi: 10.1016/j.vaccine.2013.05.094. PMID: 23973346.

14) Homer CS, Scarf V, Catling C, Davis D. Culture-based versus risk-based screening for the prevention of group B streptococcal disease in newborns: A review of national guidelines. Women Birth. 2014; 27(1): 46-51. doi: 10.1016/j.wombi.2013.09.006. PMID: 24239269.

15) Tam T, Bilinski E, Lombard E. Recolonization of group B Streptococcus (GBS) in women with prior GBS genital colonization in pregnancy. J Matern Fetal Neonatal Med. 2012; 25(10): 1987-9. doi: 10.3109/14767058.2012.670331. PMID: 22384795.

16) Ahmadzia HK, Heine RP. Diagnosis and management of group B streptococcus in pregnancy. Obstet Gynecol Clin North Am. 2014; 41(4): 629-47. doi: 10.1016/j.ogc.2014.08.009. PMID: 25454995.

17) Valkenburg-van den Berg AW, Sprij AJ, Oostvogel PM, Mutsaers JA, Renes WB, Rosendaal FR, et al. Prevalence of colonisation with group B Streptococci in pregnant women of a multi-ethnic population in The Netherlands. Eur J Obstet Gynecol Reprod Biol. 2006; 124(2): 178-83. doi: 10.1016/j.ejogrb.2005.06.007. PMID: 16026920.

18) Cools P, Jespers V, Hardy L, Crucitti T, Delany-Moretlwe S, Mwaura M, et al. A Multi-Country CrossSectional Study of Vaginal Carriage of Group B Streptococci (GBS) and Escherichia coli in Resource-Poor Settings: Prevalences and Risk Factors. PLoS One. 2016; 11(1): 0148052. doi: 10.1371/journal.pone.0148052.

19) Colicchia LC, Lauderdale DS, Du H, Adams M, Hirsch E. Recurrence of group B streptococcus colonization in successive pregnancies. J Perinatol. 2015; 35(3): 173-6. doi: 10.1038/jp.2014.185. PMID: 25321646.

20) Clifford V, Garland SM, Grimwood K. Prevention of neonatal group B streptococcus disease in the 21st century. J Paediatr Child Health. 2012; 48(9): 808-15. doi: 10.1111/j.1440-1754.2011.02203.x, PMID: 22151082 . 